CLINICAL STUDY

\title{
Genetic variants associated with persistent central obesity and the metabolic syndrome in a 12-year longitudinal study
}

\author{
Chloe Y Y Cheung ${ }^{1, *}$, Annette W K Tso ${ }^{1,3, *}$, Bernard M Y Cheung ${ }^{1}$, Aimin Xu ${ }^{1,3}$, K L Ong ${ }^{1}$, Lawrence S C Law ${ }^{1}$, \\ Nelson M S Wat ${ }^{1}$, Edward D Janus ${ }^{5}$, Pak C Sham ${ }^{2,4, \dagger}$ and Karen S L Lam ${ }^{1,3, \dagger}$ \\ ${ }^{1}$ Department of Medicine, LKS Faculty of Medicine, Queen Mary Hospital, The University of Hong Kong, 102 Pokfulam Road, Hong Kong, SAR, China, \\ ${ }^{2}$ Department of Psychiatry, LKS Faculty of Medicine, Queen Mary Hospital, The University of Hong Kong, 21 Sassoon Road, Hong Kong, SAR, China, \\ ${ }^{3}$ Research Centre of Heart, Brain, Hormone and Healthy Aging and ${ }^{4}$ Genome Research Centre, LKS Faculty of Medicine, The University of Hong Kong, \\ Hong Kong, SAR, China and ${ }^{5}$ Department of Medicine, Western Hospital, University of Melbourne, Footscray, Victoria 3011, Australia
}

(Correspondence should be addressed to K S L Lam at Department of Medicine, Queen Mary Hospital; Email: ksllam@hku.hk; P C Sham at Department of Psychiatry, Queen Mary Hospital; Email: pcsham@hkucc.hku.hk)

*(C Y Y Cheung and A W K Tso contributed equally to this work and should be considered as co-first authors)

$\dagger$ (P C Sham and K S L Lam contributed equally to the supervision of this work and are co-corresponding authors)

\begin{abstract}
Objective: Central obesity predisposes to various cardiometabolic diseases and is a key component of the metabolic syndrome (MetS). We have previously demonstrated that three obesity-susceptible single nucleotide polymorphisms (SNPs), rs10938397 (GNPDA2), rs8050136 (FTO) and rs17782313 $(M C 4 R)$, were associated with obesity and waist circumference in cross-sectional studies in the Chinese population. In this study, we investigate whether these SNPs could also predict the persistence of central obesity and MetS in subjects from the Hong Kong Cardiovascular Risk Factors Prevalence Study (CRISPS) cohort.

Design and methods: We genotyped these SNPs in i) 354 subjects with and 994 subjects without central obesity at both baseline and a 12-year follow-up, ii) 2214 subjects (816 cases and 1398 controls) in an MetS cross-sectional case-control study and iii) 225 subjects with and 1221 subjects without MetS at both baseline and the 12-year follow-up.

Results: Both FTO rs8050136 ( $P_{\text {age, sex-adjusted }}=0.019$; odds ratio $(\mathrm{OR})(95 \%$ confidence intervals $(\mathrm{CI}))$ : $1.35(1.05,1.73))$ and GNPDA2 rs10938397 $\left(P_{\text {age, sex-adjusted }}=3 \times 10^{-3} ;\right.$ OR $(95 \%$ CI $): 1.34$ $(1.11,1.63))$ were significantly associated with persistent central obesity. GNPDA2 rs10938397 was also significantly associated with $\operatorname{MetS}\left(P_{\text {age, sex-adjusted }}=0.011\right.$, OR $\left.(95 \% \mathrm{CI}): 1.20(1.04,1.38)\right)$ in the case-control study. However, none of these SNPs showed an individual association with persistent MetS. In the combined genetic risk analyses for persistent central obesity and persistent MetS, the combined genetic risk score of the three SNPs showed an OR of 1.25 (95\% CI: 1.10, 1.42; $\left.P_{\text {age, sex-adjusted }}=4.92 \times 10^{-3}\right)$ and $1.19\left(95 \%\right.$ CI: $\left.1.03,1.38 ; P_{\text {age, sex-adjusted }}=0.019\right)$ for each additional risk allele respectively.

Conclusion: This study demonstrated that FTO and GNPDA2 variants predicted persistent central obesity in the Chinese population, further supporting their importance as obesity-susceptible genes.
\end{abstract}

European Journal of Endocrinology 164 381-388

\section{Introduction}

Obesity, with a rapidly increasing prevalence all over the world, is now recognised as a global epidemic (1). Obesity, whether general or central obesity, is associated with an increased risk of developing various cardiometabolic diseases such as type 2 diabetes mellitus (T2DM), hypertension and cardiovascular diseases (CVD) (2). Using the Asian criterion for general obesity (body mass index (BMI) $\geq 27.5 \mathrm{~kg} / \mathrm{m}^{2}$ ) (3), our group recently replicated the associations of three obesity-susceptible genetic variants identified from previous Caucasian genome-wide association studies $(4,5)$ with obesity in a Chinese case-control study involving 470 obese (BMI $\geq 27.5 \mathrm{~kg} / \mathrm{m}^{2}$ ) cases and 700 normal weight controls. Three single nucleotide polymorphisms (SNPs), rs10938397 (GNPDA2), rs8050136 (FTO) and rs17782313 (MC4R), were found to be strongly associated with obesity in our Southern Chinese cohort (6). In the same study, we also observed significant associations of these three SNPs with BMI, and in the females we also observed significant associations with waist circumference (WC) in a cross-sectional extension study 
based on 1938 Southern Chinese subjects from the Hong Kong Cardiovascular Risk Factors Prevalence Study (CRISPS) cohort (6). The significant associations of the GNPDA2 SNP rs10938397 and FTO SNP rs6499640 $\left(r^{2}=1\right.$ with rs8050136 on the HapMap for Han Chinese) with obesity were further replicated in another separate study in the Chinese population (7).

Epidemiological studies in recent years have suggested that central obesity, as indicated by an increased WC or waist-hip ratio, may be more important than general obesity, as reflected by BMI, in predicting the risk of the metabolic syndrome (MetS) and CVD (8-11). Indeed, central obesity is recognised as a key component of the MetS (12), a cluster of interrelated cardiometabolic abnormalities, which also include hypertension, hyperglycaemia and dyslipidaemia (hypertriglyceridaemia and reduced high-density lipoprotein cholesterol (HDLC)) $(13,14)$. It has been suggested that central obesity plays a causative role in the pathogenesis of MetS $(12,15,16)$.

We hypothesised that individuals persistently affected by a particular condition may be under a strong influence from genetic susceptibility. Similarly, individuals who are persistently unaffected by a condition may be influenced by the protective effects conferred by certain genes. The CRISPS cohort, with 12-year longitudinal data, has allowed us to identify two such groups of individuals whom we hypothesise are likely to be genetically distinct. In this study, our major objective is to further establish the clinical significance of the three previously identified obesity-associated SNPs (rs10938397, rs8050136 and rs17782313) by evaluating their association with the persistence of central obesity and MetS. We carried out i) a longitudinal study on persistent central obesity, ii) a cross-sectional casecontrol study on MetS and iii) a longitudinal study on persistent MetS in a 12-year longitudinal study in Southern Chinese population.

\section{Methods}

\section{Subjects}

CRISPS is a population-based longitudinal study of cardiovascular risk factors, in which subjects were randomly selected from the general population in Hong Kong. Details of the CRISPS cohort were previously described (17-22). Briefly, in 1995-1996, 2895 Hong Kong Chinese (1412 males and 1483 females, aged 25-74 years) were recruited randomly using their telephone numbers (baseline). In 2000-2004, 1944 subjects (901 males, 1043 females, mean age: $52 \pm 12$ years, retention rate: $67.2 \%$ ) returned for follow-up study (CRISPS2) (22). In the years 2005-2008, 1803 subjects ( 839 males, 964 females, mean age: $56 \pm 11$ years, retention rate of baseline cohort: $62.3 \%$ ) enrolled in the latest follow-up study (CRISPS3).

In this study, out of the 2895 subjects at baseline, we only included those who had returned either to CRISPS2 or CRISPS3.

\section{Twelve-year longitudinal study for persistent central obesity}

i) Persistent central obesity $(n=354)$ included subjects who had central obesity at baseline and continued to have central obesity at CRISPS3.

ii) Persistent absence of central obesity $(n=994)$ included subjects without central obesity at baseline, who remained free of central obesity at CRISPS3 (Table 1).

\section{Cross-sectional case-control study for the MetS}

i) Cases $(n=816)$ included subjects who documented to have MetS at either baseline or CRISPS2 or CRISPS3.

ii) Controls $(n=1398)$ included subjects without MetS at baseline and subsequent follow-up visit(s) (Table 2).

\section{Twelve-year longitudinal study for persistent MetS}

i) Persistent MetS $(n=225)$ included subjects who had MetS at baseline and continued to have MetS at CRISPS3.

ii) Persistent absence of MetS (non-MetS) $(n=1221)$ included subjects without MetS at baseline who remained free of MetS at CRISPS3 (Table 2).

From the cross-sectional case-control study cohort, the subsets of cases $(n=225, \sim 28 \%)$ and controls $(n=1221, \sim 87 \%)$ who showed persistence in their phenotypes (i.e. persistent MetS or persistent absence of

Table 1 Baseline clinical characteristics of subjects in the longitudinal study for persistent central obesity. Data as mean \pm s.D.

\begin{tabular}{llll}
\hline & \multicolumn{2}{l}{ Persistent central obesity } & \\
\cline { 2 - 3 } Baseline & Present & Absent & \multirow{2}{*}{$\boldsymbol{P}$ value } \\
\hline Number & 354 & 994 & - \\
Sex (male \%) & 37.6 & 52.6 & $<0.001$ \\
Age (years) & $48.6 \pm 11.1$ & $42.9 \pm 11.4$ & $<0.001$ \\
BMl (kg/m $\left.{ }^{2}\right)$ & $28.6 \pm 3.1$ & $22.3 \pm 2.5$ & $<0.001$ \\
Waist circumference $(\mathrm{cm})$ & & & \\
$\quad$ Male & $96.2 \pm 5.2$ & $78.4 \pm 6.5$ & $<0.001$ \\
$\quad$ Female & $87.5 \pm 5.9$ & $69.1 \pm 5.3$ & $<0.001$ \\
Fasting glucose $(\mathrm{mmol} / \mathrm{l})$ & $5.6 \pm 1.4$ & $5.2 \pm 1.0$ & $<0.001$ \\
Two hours post-OGTT & $8.0 \pm 3.5$ & $6.2 \pm 2.4$ & $<0.001$ \\
$\quad$ glucose $(\mathrm{mmol} / /)$ & & & \\
Fasting insulin $(\mu \mathrm{U} / \mathrm{ml})^{\mathrm{a}}$ & $7.7(5.1-10.8)$ & $4.2(2.7-5.9)$ & $<0.001$
\end{tabular}

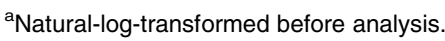


Table 2 Baseline clinical characteristics of subjects in the cross-sectional case-control study for MetS and longitudinal study for persistent MetS. Data as mean \pm S.D. or median (interquartile range). Cases are defined as the presence of MetS in either baseline or CRISPS2 or CRISPS3 follow-up. Controls are defined as the absence of MetS in both baseline and subsequent follow-up(s).

\begin{tabular}{|c|c|c|c|c|c|c|}
\hline \multirow[b]{2}{*}{ Baseline parameter } & \multicolumn{2}{|c|}{$\begin{array}{c}\text { Cross-sectional case-control } \\
\text { study for MetS }\end{array}$} & \multirow[b]{2}{*}{$P$ value } & \multicolumn{2}{|c|}{$\begin{array}{l}\text { Longitudinal study } \\
\text { for persistent MetS }\end{array}$} & \multirow[b]{2}{*}{$P$ value } \\
\hline & Case & Control & & Persistent MetS & Persistent non-MetS & \\
\hline Number & 816 & 1398 & - & 225 & 1221 & - \\
\hline Sex (male \%) & 47.7 & 46.3 & 0.527 & 47.3 & 47.6 & 0.934 \\
\hline Age (years) & $50.0 \pm 12.1$ & $43.0 \pm 11.4$ & $<0.001$ & $50.4 \pm 10.7$ & $42.3 \pm 10.9$ & $<0.001$ \\
\hline BMI $\left(\mathrm{kg} / \mathrm{m}^{2}\right)$ & $26.4 \pm 3.4$ & $22.9 \pm 3.0$ & $<0.001$ & $27.9 \pm 3.0$ & $23.0 \pm 3.0$ & $<0.001$ \\
\hline \multicolumn{7}{|l|}{ Waist circumference $(\mathrm{cm})$} \\
\hline Male & $89.4 \pm 8.5$ & $79.6 \pm 7.8$ & $<0.001$ & $93.0 \pm 6.5$ & $80.0 \pm 7.6$ & $<0.001$ \\
\hline Female & $81.9 \pm 8.6$ & $71.6 \pm 7.3$ & $<0.001$ & $86.3 \pm 7.6$ & $71.5 \pm 7.4$ & $<0.001$ \\
\hline Fasting glucose $(\mathrm{mmol} / \mathrm{l})$ & $5.8 \pm 1.7$ & $5.1 \pm 0.9$ & $<0.001$ & $6.2 \pm 1.8$ & $5.1 \pm 0.7$ & $<0.001$ \\
\hline $\begin{array}{l}\text { Two hours post-OGTT } \\
\text { glucose }(\mathrm{mmol} / \mathrm{l})\end{array}$ & $8.3 \pm 4.0$ & $5.9 \pm 1.9$ & $<0.001$ & $9.2 \pm 4.3$ & $5.9 \pm 1.7$ & $<0.001$ \\
\hline Fasting insulin $(\mu \mathrm{U} / \mathrm{ml})^{\mathrm{a}}$ & $6.6(4.6-9.9)$ & $4.1(2.8-6.0)$ & $<0.001$ & $8.3(5.7-11.3)$ & $4.2(2.9-6.2)$ & $<0.001$ \\
\hline
\end{tabular}

${ }^{\mathrm{a} N a t u r a l-l o g-t r a n s f o r m e d ~ b e f o r e ~ a n a l y s i s . ~}$

MetS) from baseline to CRISPS3 were therefore included respectively as the cases and controls of the 12-year longitudinal study for persistent MetS (Table 2).

\section{Anthropometric and biochemical measurements}

All subjects were assessed after an overnight $10 \mathrm{~h}$ fast. The anthropometric (including blood pressure, weight, height, BMI, WC and hip circumference) and biochemical parameters (including plasma glucose, insulin and lipids) were measured as previously described $(10,22-25)$. All subjects, except those with diagnosed diabetes on medical treatment, underwent a $75 \mathrm{~g}$ oral glucose tolerance test (OGTT). Venous blood samples were taken for clinical biochemistry and genetic analyses. All participants gave written informed consent, and the study protocol was approved by the ethics committee of the University of Hong Kong.

\section{Definition of central obesity and MetS}

Central obesity was defined by $\mathrm{WC} \geq 90 \mathrm{~cm}$ in men or $\geq 80 \mathrm{~cm}$ in women as suggested for Asian populations (26). MetS was defined according to the modified criteria proposed in the joint scientific statement by the International Diabetes Federation Task Force on Epidemiology and Prevention; National Heart, Lung, and Blood Institute; American Heart Association; World Heart Federation; International Atherosclerosis Society; and International Association for the Study of Obesity (27). An individual would be classified as having MetS if three out of the five following criteria were fulfilled:

i) $W C \geq 90 \mathrm{~cm}$ in men or $\geq 80 \mathrm{~cm}$ in women.

ii) Triglyceride concentration $\geq 150 \mathrm{mg} / \mathrm{dl}$ $(1.7 \mathrm{mmol} / \mathrm{l})$. iii) HDLC concentration $<40 \mathrm{mg} / \mathrm{dl}(1.0 \mathrm{mmol} / \mathrm{l})$ in males or $<50 \mathrm{mg} / \mathrm{dl}(1.3 \mathrm{mmol} / \mathrm{l})$ in females.

iv) Systolic blood pressure $\geq 130 \mathrm{mmHg}$ and/or diastolic blood pressure $\geq 85 \mathrm{mmHg}$.

v) Fasting blood glucose $\geq 100 \mathrm{mg} / \mathrm{dl}(\geq 5.6 \mathrm{mmol} / \mathrm{l})$.

Individuals receiving specific treatment for a criterion were considered as fulfilling that criterion.

\section{Genetic analysis}

The three SNPs, rs10938397 (GNPDA2), rs8050136 (FTO) and rs17782313 (MC4R), that showed the most promising associations with obesity in our previous casecontrol study (6) were examined for association with persistent central obesity and MetS in this study. Genomic DNA was extracted from available buffy coat samples by the standard phenol-chloroform extraction procedures. Genotypes of the three SNPs from 1938 subjects were obtained from our previous study (6). The three SNPs were genotyped in the remaining subjects by the TaqMan Pre-designed SNP Genotyping Assay (rs10938397: assay ID: C_1594245_10; rs8050136: assay ID: C__031259 _10; rs 17782313: assay ID: C_32667060_10; Applied Biosystems, Foster City, CA, USA). PCRs were performed in the GeneAmpPCR System 9700 thermal cycler according to the manufacturer's protocols, and assay products were analysed using Applied Biosystems PRISM 7000 Sequence Detection System for fluorescence intensity detection. At least two negative controls (without DNA) were included for the identification of contaminations in each 96-well plate. The Hardy-Weinberg equilibrium (HWE) for each SNP was examined by the De Finetti program available at http://ihg2.helmholtz-muenchen. de/cgi-bin/hw/hwa1.pl. HWE $P$ values were $>0.05$ in the case and control subjects for all three SNPs. Average successful genotyping call rate and concordance rate were 99.46 and $98.33 \%$ respectively. 


\section{Statistical analysis}

All statistical analyses were performed with SPSS (Version 16.0; Chicago, IL, USA). All continuous variables are expressed as mean \pm s.D. or median with interquartile range as appropriate. All variables that did not follow a normal distribution in the KolmogorovSmirnov test were log-transformed before the analysis. Logistic regressions under the additive model were used to estimate the associations of each SNP with central obesity and MetS. A two-tailed $P$ value of $<0.05$ was considered as statistically significant. The expected power of study was calculated using the Genetic Power Calculator available at http://pngu.mgh.harvard. $\mathrm{edu} / \sim \mathrm{purcell} / \mathrm{gpc} /$ (28). The combined genetic risk score (GRS) for the three SNPs studied were calculated by the simple count (count GRS) method (i.e. counting the number of risk alleles where $0,1,2$ correspond to genotypes containing zero, one and two risk alleles respectively and a sum score was created out of the maximum number of six risk alleles for three variants) (29). Thirty-four subjects with missing genotypes for any of the three SNPs were excluded from the combined genetic risk analyses $(25$ controls and 9 cases from the MetS case-control study; 17 subjects from the persistent central obesity longitudinal study; and 24 subjects from the persistent MetS longitudinal study). The receiver operating characteristic curves were generated and the corresponding area under the curves (AUCs) were calculated with SPSS (Version 16.0).

\section{Results}

The three previously identified obesity-associated SNPs (rs10938397, rs8050136 and rs17782313) were genotyped in subjects from the population-based CRISPS cohort and examined for their associations with i) persistent central obesity, ii) MetS and iii) persistent MetS. The baseline clinical characteristics of subjects in these three studies were shown in Tables 1 and 2.

\section{Association with persistent central obesity in the longitudinal prospective study}

This study involved 354 subjects with persistent central obesity and 994 subjects with persistent absence of central obesity. Table 3 shows the results of the association analyses of the three SNPs and the combined GRS with persistent central obesity. Significant associations with persistent central obesity were observed in the FTO SNP rs8050136 $\left(P_{\text {age, sex-adjusted }}=\right.$ 0.019 ; odds ratio $(\mathrm{OR})(95 \%$ confidence intervals $(\mathrm{CI}))$ : $1.35(1.05,1.73))$ and GNPDA2 SNP rs10938397 $\left(P_{\text {age, sex-adjusted }}=3 \times 10^{-3}\right.$; OR $(95 \% \mathrm{CI}): 1.34$ (1.11, 1.63)). After Bonferroni correction for multiple testing, the association of the GNPDA2 SNP rs10938397 remained significant $\left(P=9 \times 10^{-3}\right)$ and there was a

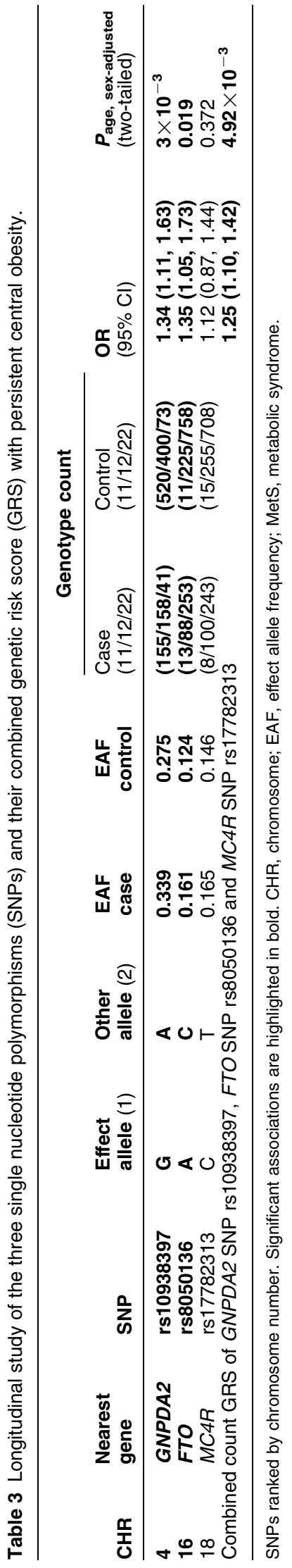



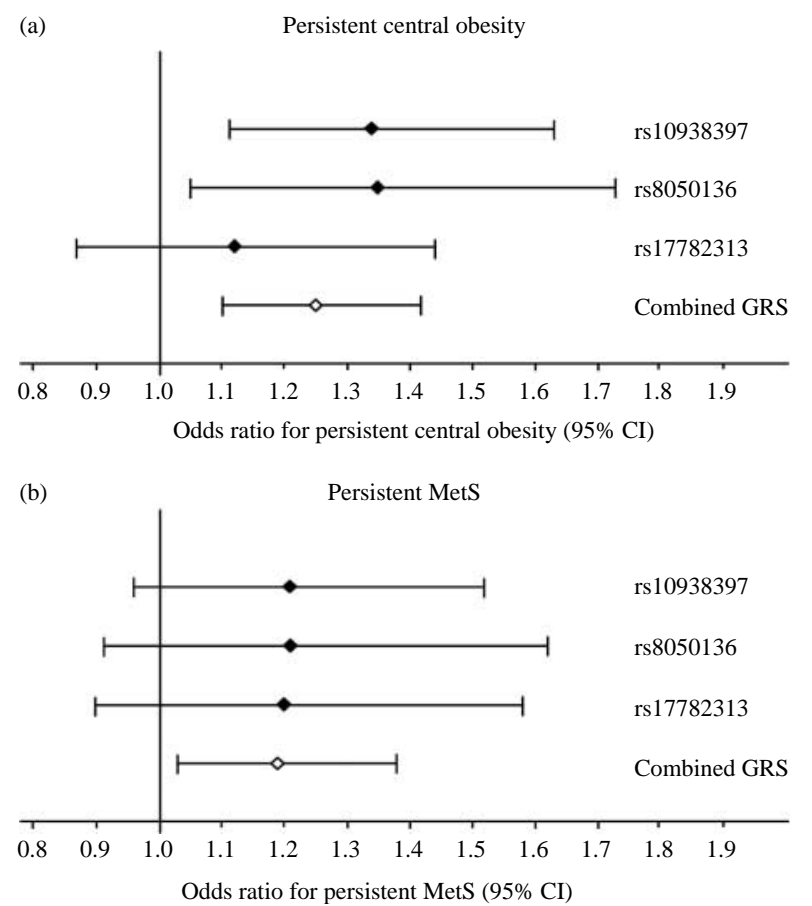

Figure 1 Forest plot showing the risk of persistent central obesity and persistent MetS. OR $(95 \% \mathrm{Cl})$ for association of the GNPDA2 SNP rs10938397, FTO SNP rs8050136 and MC4R SNP rs17782313 and their combined GRS with (a) persistent central obesity and (b) persistent MetS.

trend for association of the FTO SNP rs8050136 with persistent central obesity $(P=0.057)$. In the combined genetic risk analysis, the combined GRS showed an OR of 1.25 (95\% CI: 1.10, 1.42; $P_{\text {age, sex-adjusted }}=$ $4.92 \times 10^{-3}, \quad$ AUC $\left.=0.565\right)$ for each additional risk allele (Fig. 1a).

\section{Association with MetS in the cross-sectional case-control study}

Having observed the significant associations with persistent central obesity, we further investigated whether these SNPs would show significant associations with MetS in a cross-sectional case-control study involving 816 cases and 1398 controls. Table 4 shows the results of the association analyses of these three SNPs and the combined GRS with MetS. The GNPDA2 SNP rs10938397 was the only SNP that showed a significant association with MetS ( $P_{\text {age, sex-adjusted }}=0.011$; OR $(95 \%$ CI): $1.20(1.04,1.38))$. The association of rs10938397 with MetS remained significant even after Bonferroni correction for multiple testing $(P=0.033)$. However, this association became insignificant after further adjustment for BMI ( $P_{\text {age, sex, BMI-adjusted }}=0.100$; OR $(95 \%$ CI): $1.14(0.98,1.34))$. The count GRS showed an OR of $1.10\left(95 \%\right.$ CI: $1.01,1.21 ; P_{\text {age, sex-adjusted }}=0.036$, $\mathrm{AUC}=0.530$ ) for each additional risk allele in the combined genetic risk analysis.

\section{Association with persistent MetS in the longitudinal study}

Finally, we evaluated the associations of these three SNPs with persistent MetS in the prospective population-based CRISPS cohort involving 225 subjects with persistent MetS and 1221 subjects with persistent absence of MetS (non-MetS). Table 4 shows the results of the association analyses of the three SNPs and the combined GRS with persistent MetS. Figure 1b shows the ORs and 95\% CI for association with persistent MetS for these three SNPs. Although significant individual associations of the three SNPs with persistent MetS were not observed, the combined GRS of these SNPs showed an OR of $1.19(95 \%$ CI: $1.03,1.38 ; P_{\text {age, sex-adjusted }}=0.019, \mathrm{AUC}=0.547$ ) for each additional risk allele. However, this association was abolished on adjustment for either fasting insulin level $\left(P_{\text {age, sex, fasting insulin level-adjusted }}=0.282 ; \mathrm{OR}(95 \% \mathrm{CI})\right.$ : $1.10(0.92,1.32))$ or BMI $\left(P_{\text {age, sex, BMI-adjusted }}=0.201\right.$; OR $(95 \%$ CI): $1.12(0.94,1.35))$, suggesting that the effects of these SNPs are likely to be mediated through obesity-related insulin resistance and adiposity.

\section{Discussion}

In this study, we investigated the associations of three obesity-associated SNPs (rs10938937, rs8050136 and rs17782313) identified from recent genome-wide association studies $(4,5)$ with persisting central obesity and MetS using a longitudinal prospective study. The allele frequencies of these three SNPs observed in this study were similar to those reported in the HapMap Han Chinese population. We have successfully detected significant associations of the GNPDA2 SNP rs10938397 and the well-known FTO SNP rs8050136 with persistent central obesity in the 12-year longitudinal study. We also observed the association of the GNPDA2 SNP rs10938397 with MetS. The combined genetic risk of all three SNPs showed significant associations with both persistent central obesity and persistent MetS. However, the association of the combined GRS with persistent MetS was abolished following adjustment for fasting insulin level or BMI, suggesting that the increased risk conferred by these SNPs may be secondary to their association with obesity and/or insulin resistance. We failed to detect significant associations of rs17782313 with central obesity or MetS in this study, even though this SNP or another MC4R SNP rs12970134 (which is in high LD with rs17782313 - LD $=0.81$ in Han Chinese according to HapMap) has previously been shown to be associated with insulin resistance, WC, obesity, fat mass, height and weight in Caucasians $(30,31)$. This could have been due to our small sample size as compared with the largerscale studies in the European populations and the relatively wide $95 \%$ CI. 


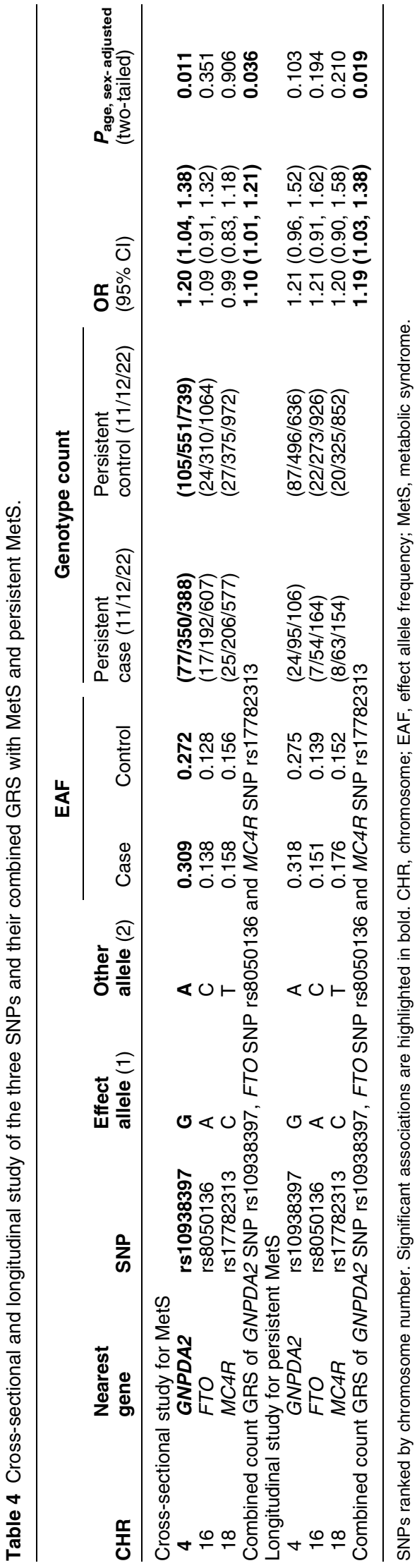

We observed significant association of the GNPDA2 and FTO SNPs with persistent central obesity in the 12-year longitudinal study. As central obesity represents one of the best predictors for MetS in our population (10), it is therefore not surprising that we also observed a significant association of the combined genetic risk of the three SNPs with persistent MetS although individual association of the three SNPs with persistent MetS was not observed. Indeed, the role of central obesity was considered so significant in the development of MetS that central obesity, as defined by the ethnic-specific WC, was previously proposed by the International Diabetes Federation as a prerequisite for the definition of MetS (13).

Apart from being a good predictor for MetS, central obesity has been suggested to be involved in the development of cardiometabolic disorders, such as T2DM and CVD. In our population, central obesity has been demonstrated to have a greater contribution to the development of cardiovascular risk than general obesity (32) and was also shown to be independently associated with worsening of glucose intolerance (23). There is therefore an urgent need to identify individuals at risk of having persistent central obesity for early interventions such as lifestyle modifications and individualised management strategies, in order to prevent these obesity-related diseases.

The major limitation of this study is our relatively small sample size. Our sample size may not be able to provide sufficient power to detect the significance for some of the associations as the effect sizes and allele frequencies of the SNPs studied were relatively low. At a significance level of 0.05, our sample size for the longitudinal persistent central obesity study provided more than $90 \%$ power to detect a significant association of the FTO SNP (rs8050135) and GNPDA2 SNP (rs10938397) with the observed ORs, by assuming a prevalence of 0.323 (average prevalence of central obesity at baseline, CRISPS2 and CRISPS3). However, our sample size for the longitudinal persistent MetS study could only achieve $40-60 \%$ power to detect a persistent MetS-susceptible SNP, assuming a disease prevalence of 0.238 (average prevalence of MetS at baseline, CRISPS2 and CRISPS3), likely to be due to the small observed ORs. Larger prospective studies of these genetic variants for predicting central obesity and MetS would be of great interest. We should also acknowledge that as central obesity is the key component of MetS, the significant association with MetS, observed in the persistent central obesity-associated SNP, rs10938397, could be due to the fact that centrally obese subjects are more likely to develop MetS. Moreover, the prospective cases and controls were, in fact, subsets of the cases and controls respectively in the cross-sectional study for MetS. Out of the 816 cases and 1398 controls of the cross-sectional study for MetS, $225(\sim 28 \%)$ cases and $1221(\sim 87 \%)$ controls fulfilled the inclusion criteria as subjects with persistent MetS and persistent absence 
of MetS respectively for the longitudinal study for persistent MetS. We have simply identified, among the baseline MetS cases and non-MetS controls, the respective subset that is likely to have a stronger genetic influence because of the apparent persistence of their phenotype. Another large independent populationbased prospective cohort would enable us to confirm our current findings.

In conclusion, we have demonstrated in a 12-year longitudinal study that the FTO SNP rs8050136 and GNPDA2 SNP rs10938937 may be useful for predicting persistent central obesity, a key component of MetS, in the Southern Chinese population. However, whether these genetic variants also confer susceptibility to the development of central obesity or MetS in other ethnic groups remains to be confirmed. Further investigations of these genetic variants in other ethnic groups, whether in the form of cross-sectional or longitudinal studies, would be of great interest. With the increasing number of central obesity-susceptible genes being identified, their combined genetic risk might eventually allow us to identify individuals who are at high risk of developing central obesity. Importantly, this information may advance our understanding of the pathogenesis of obesity and MetS and from that may even lead to new therapeutic approaches. The GNPDA2 gene appeared to be an interesting gene, which might play a role in the development of metabolic disorders, such as obesity and MetS. Further studies to explore the functional relevance of this gene and fine-mapping studies to identify the causative disease-susceptible genetic variants are warranted. Availability of sufficiently large sample size remains one of the issues hindering the progression in genetic studies to detect variants with modest effect sizes. The resolution of this problem would rely on the collaborations of multiple research groups.

\section{Declaration of interest}

The authors declare that there is no conflict of interest that could be perceived as prejudicing the impartiality of the research reported.

\section{Funding}

This work was supported by a grant from the Hong Kong Research Grant Council (GRF7802/10).

\section{Acknowledgements}

C Y Y Cheung and K L Ong are the recipients of the University of Hong Kong postgraduate fellowships.

\section{References}

1 World Health Organisation Fact sheet: obesity and overweight. Geneva: WHO. 2006 Available at: http://www.who.int/mediacentre/factsheets/fs311/en/print.html. Accessed 10 May 2009.
2 Bray GA. Medical consequences of obesity. Journal of Clinical Endocrinology and Metabolism 200489 2583-2589. (doi:10. 1210/jc.2004-0535)

3 WHO Expert Consultation. Appropriate body-mass index for Asian populations and its implications for policy and intervention strategies. Lancet 2004363 157-163. (doi:10.1016/S01406736(03)15268-3)

4 Thorleifsson G, Walters GB, Gudbjartsson DF, Steinthorsdottir V, Sulem P, Helgadottir A, Styrkarsdottir U, Gretarsdottir S, Thorlacius S, Jonsdottir I, Jonsdottir T, Olafsdottir EJ, Olafsdottir GH, Jonsson T, Jonsson F, Borch-Johnsen K, Hansen T, Andersen G, Jorgensen T, Lauritzen T, Aben KK, Verbeek AL, Roeleveld N, Kampman E, Yanek LR, Becker LC, Tryggvadottir L, Rafnar T, Becker DM, Gulcher J, Kiemeney LA, Pedersen O, Kong A, Thorsteinsdottir U \& Stefansson K. Genome-wide association yields new sequence variants at seven loci that associate with measures of obesity. Nature Genetics 200941 18-24. (doi:10.1038/ng.274)

5 Willer CJ, Speliotes EK, Loos RJ, Li S, Lindgren CM, Heid IM, Berndt SI, Elliott AL, Jackson AU, Lamina C, Lettre G, Lim N, Lyon HN, McCarroll SA, Papadakis K, Qi L, Randall JC, Roccasecca RM, Sanna S, Scheet P, Weedon MN, Wheeler E, Zhao JH, Jacobs LC, Prokopenko I, Soranzo N, Tanaka T, Timpson NJ, Almgren P, Bennett A, Bergman RN, Bingham SA, Bonnycastle LL, Brown M, Burtt NP, Chines P, Coin L, Collins FS, Connell JM, Cooper C, Smith GD, Dennison EM, Deodhar P, Elliott P, Erdos MR, Estrada K, Evans DM, Gianniny L, Gieger C, Gillson CJ, Guiducci C, Hackett R, Hadley D, Hall AS, Havulinna AS, Hebebrand J, Hofman A, Isomaa B, Jacobs KB, Johnson T, Jousilahti P, Jovanovic Z, Khaw KT, Kraft P, Kuokkanen M, Kuusisto J, Laitinen J, Lakatta EG, Luan J, Luben RN, Mangino M, McArdle WL, Meitinger T, Mulas A, Munroe PB, Narisu N, Ness AR, Northstone K, O'Rahilly S, Purmann C, Rees MG, Ridderstrale M, Ring SM, Rivadeneira F, Ruokonen A, Sandhu MS, Saramies J, Scott LJ, Scuteri A, Silander K, Sims MA, Song K, Stephens J, Stevens S, Stringham HM, Tung YC, Valle TT, Van Duijn CM, Vimaleswaran KS, Vollenweider P, Waeber G, Wallace C, Watanabe RM, Waterworth DM, Watkins N, Witteman JC, Zeggini E, Zhai G, Zillikens MC, Altshuler D, Caulfield MJ, Chanock SJ, Farooqi IS, Ferrucci L, Guralnik JM, Hattersley AT, Hu FB, Jarvelin MR, Laakso M, Mooser V, Ong KK, Ouwehand WH, Salomaa V, Samani NJ, Spector TD, Tuomi T, Tuomilehto J, Uda M, Uitterlinden AG, Wareham NJ, Deloukas P, Frayling TM, Groop LC, Hayes RB, Hunter DJ, Mohlke KL, Peltonen L, Schlessinger D, Strachan DP, Wichmann HE, McCarthy MI, Boehnke M, Barroso I, Abecasis GR \& Hirschhorn JN. Six new loci associated with body mass index highlight a neuronal influence on body weight regulation. Nature Genetics 200941 25-34. (doi:10.1038/ng.287)

6 Cheung C, Tso A, Cheung B, Xu A, Ong K, Fong C, Wat N, Janus E, Sham P \& Lam K. Obesity susceptibility genetic variants identified from recent genome-wide association studies: implications in a Chinese population. Journal of Clinical Endocrinology and Metabolism 201095 1395-1403. (doi:10.1210/jc.2009-1465)

7 Ng MC, Tam CH, So WY, Ho JS, Chan AW, Lee HM, Wang Y, Lam VK, Chan JC \& Ma RC. Implication of genetic variants near NEGR1, SEC16B, TMEM18, ETV5/DGKG, GNPDA2, LIN7C/BDNF, MTCH2, BCDIN3D/FAIM2, SH2B1, FTO, MC4R, and KCTD15 with obesity and type 2 diabetes in 7705 Chinese. Journal of Clinical Endocrinology and Metabolism 201095 2418-2425. (doi:10. 1210/jc.2009-2077)

8 Grundy SM. Obesity, metabolic syndrome, and coronary atherosclerosis. Circulation 2002105 2696-2698. (doi:10.1161/01. CIR.0000020650.86137.84)

9 Welborn TA \& Dhaliwal SS. Preferred clinical measures of central obesity for predicting mortality. European Journal of Clinical Nutrition 200761 1373-1379. (doi:10.1038/sj.ejcn.1602656)

10 Cheung BM, Wat NM, Tam S, Thomas GN, Leung GM, Cheng CH, Woo J, Janus ED, Lau CP, Lam TH \& Lam KS. Components of the metabolic syndrome predictive of its development: a 6-year longitudinal study in Hong Kong Chinese. Clinical Endocrinology 200868 730-737. (doi:10.1111/j.1365-2265.2007.03110.x) 
11 Sowers JR. Obesity and cardiovascular disease. Clinical Chemistry 199844 1821-1825.

12 Despres JP \& Lemieux I. Abdominal obesity and metabolic syndrome. Nature 2006444 881-887. (doi:10.1038/nature05488)

13 Alberti KG, Zimmet P \& Shaw J. The metabolic syndrome - a new worldwide definition. Lancet 2005366 1059-1062. (doi:10. 1016/S0140-6736(05)67402-8)

14 Grundy SM, Cleeman JI, Daniels SR, Donato KA, Eckel RH, Franklin BA, Gordon DJ, Krauss RM, Savage PJ, Smith SC Jr, Spertus JA \& Costa F. Diagnosis and management of the metabolic syndrome: an American Heart Association/National Heart, Lung, and Blood Institute Scientific Statement. Circulation 2005112 2735-2752. (doi:10.1161/CIRCULATIONAHA.105. 169404)

15 Maison P, Byrne CD, Hales CN, Day NE \& Wareham NJ. Do different dimensions of the metabolic syndrome change together over time? Evidence supporting obesity as the central feature Diabetes Care 200124 1758-1763. (doi:10.2337/diacare.24. 10.1758)

16 Liese AD, Mayer-Davis EJ, Tyroler HA, Davis CE, Keil U, Duncan BB $\&$ Heiss G. Development of the multiple metabolic syndrome in the ARIC cohort: joint contribution of insulin, BMI, and WHR. Atherosclerosis risk in communities. Annals of Epidemiology 1997 7 407-416. (doi:10.1016/S1047-2797(97)00047-1)

17 Lam TH, Liu LJ, Janus ED, Bourke C \& Hedley AJ. The relationship between fibrinogen and other coronary heart disease risk factors in a Chinese population. Atherosclerosis 1999143 405-413. (doi:10.1016/S0021-9150(98)00294-9)

18 Lam TH, Liu LJ, Janus ED, Lam KS \& Hedley AJ. Fibrinogen, other cardiovascular risk factors and diabetes mellitus in Hong Kong: a community with high prevalence of type 2 diabetes mellitus and impaired glucose tolerance. Diabetic Medicine 200017 798-806. (doi:10.1046/j.1464-5491.2000.00384.x)

19 Janus ED. Epidemiology of cardiovascular risk factors in Hong Kong. Clinical and Experimental Pharmacology \& Physiology 1997 24 987-988. (doi:10.1111/j.1440-1681.1997.tb02736.x)

20 Janus ED, Watt NM, Lam KS, Cockram CS, Siu ST, Liu LJ \& Lam TH. The prevalence of diabetes, association with cardiovascular risk factors and implications of diagnostic criteria (ADA 1997 and WHO 1998) in a 1996 community-based population study in Hong Kong Chinese. Hong Kong Cardiovascular Risk Factor Steering Committee. American Diabetes Association. Diabetic Medicine 200017 741-745. (doi:10.1046/j.1464-5491.2000. 00376.x)

21 Thomas GN, Ho SY, Janus ED, Lam KS, Hedley AJ \& Lam TH. The US National Cholesterol Education Programme Adult Treatment Panel III (NCEPATP III) prevalence of the metabolic syndrome in a Chinese population. Diabetes Research and Clinical Practice 200567 251-257. (doi:10.1016/j.diabres.2004.07.022)

22 Cheung BM, Wat NM, Man YB, Tam S, Thomas GN, Leung GM, Cheng $\mathrm{CH}$, Woo J, Janus ED, Lau CP, Lam TH \& Lam KS. Development of diabetes in Chinese with the metabolic syndrome: a 6-year prospective study. Diabetes Care 200730 1430-1436. (doi:10.2337/dc06-1820)

23 Wat NM, Lam TH, Janus ED \& Lam KS. Central obesity predicts the worsening of glycemia in Southern Chinese. International Journal of Obesity and Related Metabolic Disorders 200125 1789-1793. (doi:10.1038/sj.ijo.0801834)

24 Tso AW, Sham PC, Wat NM, Xu A, Cheung BM, Rong R, Fong CH, $\mathrm{Xu}$ JY, Cheng KK, Janus ED \& Lam KS. Polymorphisms of the gene encoding adiponectin and glycaemic outcome of Chinese subjects with impaired glucose tolerance: a 5-year follow-up study. Diabetologia 200649 1806-1815. (doi:10.1007/s00125-0060324-2)
25 Tan KC, Wat NM, Tam SC, Janus ED, Lam TH \& Lam KS. C-reactive protein predicts the deterioration of glycemia in Chinese subjects with impaired glucose tolerance. Diabetes Care 200326 23232328. (doi:10.2337/diacare.26.8.2323)

26 Hara K, Matsushita Y, Horikoshi M, Yoshiike N, Yokoyama T, Tanaka H \& Kadowaki T. A proposal for the cutoff point of waist circumference for the diagnosis of metabolic syndrome in the Japanese population. Diabetes Care 200629 1123-1124. (doi:10. 2337/dc05-2540)

27 Alberti KG, Eckel RH, Grundy SM, Zimmet PZ, Cleeman JI, Donato KA, Fruchart JC, James WP, Loria CM \& Smith SC Jr. Harmonizing the metabolic syndrome: a joint interim statement of the International Diabetes Federation Task Force on Epidemiology and Prevention; National Heart, Lung, and Blood Institute; American Heart Association; World Heart Federation; International Atherosclerosis Society; and International Association for the Study of Obesity. Circulation 2009120 1640-1645. (doi:10.1161/CIRCULATIONAHA.109.192644)

28 Purcell S, Cherny SS \& Sham PC. Genetic power calculator: design of linkage and association genetic mapping studies of complex traits. Bioinformatics 200319 149-150. (doi:10.1093/bioinformatics/19.1.149)

29 Cornelis MC, Qi L, Zhang C, Kraft P, Manson J, Cai T, Hunter DJ \& $\mathrm{Hu}$ FB. Joint effects of common genetic variants on the risk for type 2 diabetes in U.S. men and women of European ancestry. Annals of Internal Medicine 2009150 541-550.

30 Loos RJ, Lindgren CM, Li S, Wheeler E, Zhao JH, Prokopenko I, Inouye M, Freathy RM, Attwood AP, Beckmann JS, Berndt SI, Jacobs KB, Chanock SJ, Hayes RB, Bergmann S, Bennett AJ, Bingham SA, Bochud M, Brown M, Cauchi S, Connell JM, Cooper C, Smith GD, Day I, Dina C, De S, Dermitzakis ET, Doney AS, Elliott KS, Elliott P, Evans DM, Sadaf Farooqi I, Froguel P, Ghori J, Groves CJ, Gwilliam R, Hadley D, Hall AS, Hattersley AT, Hebebrand J, Heid IM, Lamina C, Gieger C, Illig T, Meitinger T, Wichmann HE, Herrera B, Hinney A, Hunt SE, Jarvelin MR, Johnson T, Jolley JD, Karpe F, Keniry A, Khaw KT, Luben RN, Mangino M, Marchini J, McArdle WL, McGinnis R, Meyre D, Munroe PB, Morris AD, Ness AR, Neville MJ, Nica AC, Ong KK, O’Rahilly S, Owen KR, Palmer CN, Papadakis K, Potter S, Pouta A, Qi L, Randall JC, Rayner NW, Ring SM, Sandhu MS, Scherag A, Sims MA, Song K, Soranzo N, Speliotes EK, Syddall HE, Teichmann SA, Timpson NJ, Tobias JH, Uda M, Vogel CI, Wallace C, Waterworth DM, Weedon MN, Willer CJ, Wraight VL, Yuan X, Zeggini E, Hirschhorn JN, Strachan DP, Ouwehand WH, Caulfield MJ, Samani NJ, Frayling TM, Vollenweider P, Waeber G, Mooser V, Deloukas P, McCarthy MI, Wareham NJ, Barroso I, Kraft P, Hankinson SE, Hunter DJ, Hu FB, Lyon HN, Voight BF, Ridderstrale M, Groop L, Scheet P, Sanna S, Abecasis GR, Albai G, Nagaraja R, Schlessinger D, Jackson AU, Tuomilehto J, Collins FS, Boehnke M \& Mohlke KL. Common variants near MC4R are associated with fat mass, weight and risk of obesity. Nature Genetics 200840 768-775. (doi:10.1038/ng.140)

31 Chambers JC, Elliott P, Zabaneh D, Zhang W, Li Y, Froguel P, Balding D, Scott J \& Kooner JS. Common genetic variation near MC4R is associated with waist circumference and insulin resistance. Nature Genetics 200840 716-718. (doi:10.1038/ng.156)

32 Thomas GN, Ho SY, Lam KS, Janus ED, Hedley AJ \& Lam TH. Impact of obesity and body fat distribution on cardiovascular risk factors in Hong Kong Chinese. Obesity Research 200412 18051813. (doi:10.1038/oby.2004.224)

Received 16 November 2010

Accepted 8 December 2010 